\title{
Untranslatability: Interdisciplinary Perspectives
}

LARGe, DunCAN; Motoko AKashi; WANDA JozWIKOWSKA and EMILY ROSE. (eds.). 2019. Untranslatability: Interdisciplinary Perspectives. Routledge Advances in Translation and Interpreting Studies. New York: Routledge.

Reviewed by VINAY S. M.

Split into three parts; part one focuses on the theoretical and philosophical construction of Untranslatability, while part two brings to the readers certain select texts of poetry and prose to testify the understanding of Untranslatability with explicit case studies to mark the usage of concept in literary world and the last part documents the practical implications and conceptions of Untranslatability. There are in-total thirteen papers, authored by thirteen different experts who hold thirteen distinctive interdisciplinary perspectives of Untranslatability. Unlike other books that go on in-depth about a particular aspect of Untranslatability and explore the same old traditional notion of Target Texts with the Source Texts, in various terms and bring similar instances through multiple papers, this volume promises the reader (especially students of Translation Studies and Interpreting Studies) to bear light on various ideas hidden behind the conceptualization of Untranslatability.

Barbara Cassin's paper is more of a dialogue between Humbolt and her ideas, denouncing the myth of Untranslatability. This article provides a picture towards a positive approach for a translator, pronouncing 'translation' as a 'never ending process'. "It is untranslated, so be it, but everything can be said in every language; therefore, we can translate it, only it always remains to be (re)translated."

It is read in Theo Hermans paper that there always is a remedy of the Untraslatable, provided the attitude of a translator should be tireless and he may be blessed with a tremendous 
amount of time, and, of a limitless supply of words. The author also opens up dialogues on the tentativeness of cross-cultural understandings in the course of the paper. Further, we come across Kirsten Malmkjaer and Duncan Large, announcing that Untranslatability is never 'vicious' but an interesting concept of investigating and that Translatability as an act of 'resourceful creative responses'.

David Gramling in his paper ( $6^{\text {th }}$ Unit in Part I) gives an intriguing outlook to the whole concept of Untranslatability. His words define a mocking gesture towards those boasting writers (non-translators) and goes on to reveal that the whole construct of Untranslatability has, in fact, been a game of challenge to the practicing translators. He cites numerous examples and develops what he calls ten 'templates' to argue against the popular 1990's notion of 'right to Untranslatability' in his paper and gives a new shape in perceiving Untranslatability as a challenge for most translators, who have often overcome its very definition in their works with triumph and have left gaps for new translation to come in due course.

Philip Wilson in Translation and Mysticism discusses the issue of Indeterminacy in Translation, stating the instability of the meaning and usage of words in a language and the indeterminacy of the philosophical terms like 'logos', which also proves to be a challenging one if the given context in which the term is applied is unclear or is unspecified. The mention of Goethe's Faust, and the controversial rendition of 'logos' by Faust is interesting to determine that this instability of meaning and interpretation of 'words' has long been observed, talked, debated and written. Another aspect that the reader will find here is that the indeterminacy in 'mystics' is highly due to the effect of the persuasive use of language on readers that in turn gives rise to multiple meanings. The construct of meaning in target texts are the results of the 
translator's attitude to deal the sensitiveness of the use of language in mysticism.

Simon Everett in his paper Remembered Hills brings out the concept of 'Untranslatability' in the context of the Chinese T'ang Poetry and displays a variety of interesting aspects and the peculiarities of the Chinese poetry with respect to the unique patterns of tones. He goes on to draw a general conclusion that the major problem in translating $T^{\prime}$ ang Poetry is the immense baggage of material content in the language of $T^{\prime}$ 'ang that pose as a challenge in translating them into English language. We find a couple of translations of Li Po's poems in this paper where we learn that poet-translators have ventured many techniques in translating Li Po's poems, while one such translation stands unique and, as Everett claims, is a best example of 'cultural resonance'.

In the ninth unit, Helen Gibson paper exposes Ciaron Carson, a Belfast port and translator's practice of 'substitutability' in translation of Dante's Inferno along with several other examples of his works. Using Carson's, The Inferno, Gibson attempts to draw an understanding of the shifts between translatability and untranslatability, which, she further sees creating a complex and subtle situation leading to peculiar linguistic world. She also pictures an example in the paper, of the Canto XVIII of Carson's The Inferno. The reader is exposed here to the instability of a language across time and region, ultimately viewing translation and re-translation as a practice of weaving inventive webs from the source texts. One such inventive web, as mentioned in the paper is Carson's The Inferno that displays his personal linguistic revelation.

In Wanda Jozwikowska's Resistance as Cultural Untranslatability, we come across the nature of effect of the factors other than the properties of a source text have towards the cultural untranslatability that acts as a hindrance in 
reaching out to the masses. In doing it, she brings out her six source-factors, and they comprise as the source text's inherent resistance to translation. She also traces out the influence of Polish Jewish writers such as Bruno Schull and others' influences on the American and English audience and maps the difference of the readership among the two. In addition to presenting the inherent textual factors, the paper also attempts at suggesting some of the potential measures to overcome this unique resistance, to give this less touched literature, its deserved readership.

In the eleventh paper, Translating a Transgender Memoir, Emily Rose discusses her own encounter in translating an already translated memoir of a $17^{\text {th }}$ century Spanish personality by name 'Catalina de Erauso'. Rose also mentions other subsequent translations of this memoir and postulates a planned system of fonts to denote the gender of the word used in translation. These curious fonts appear in her paper in table 11.1. Efforts of this paper are an important gesture towards an inclusive approach in recognizing the identities hidden and more often excluded in traditional translation practices.

The interesting aspect of the twelfth paper in the book, by Andrea Stojilkov is that she has taken an issue that she is hypothetical about, for the issue is surrounded while translating Nele Krajlic, a Bosnian musician's autobiographical work - Fajront $u$ Sarajevu. This hypothetical issue appears to be systematically put into key points in the paper such as the 'Linguistic Problem', wherein she discusses the virtue of the texts' potential diversity of dialects and variants of language(s) within the geographical region(s) dealt in the work. This paper acts like an invitation for translators and also is a directive guideline for translation.

Joanna Drugans's paper, the thirteenth paper and but the last one in the book is designated in its third part. It was a wonder 
why this paper, alone, was kept apart, and while perusing its contents and its rather pragmatic argument I realised that the paper is on a different level, totally dealing with a real-life scenario where Untranslatability is observed, oftentimes leading to fatalities. The author claims, in an interesting line of argument that most untranslatability occurs due to economic and political reason, that the untranslatables are a result of an improper system of funding, planning and due poor decisions. The scenarios mentioned are all on the 'maternity' and maternity related situations. This interesting research work leaves the student with a new point-of-view and opens up new scope and new angles to look at the frequently occurring concept of Untranslatability in this book.

This collection of thirteen papers is a key read for a student of Translation Studies and translators in general. The authors employ language that is comprehensible to all in general. Therefore, it should be a necessary piece of writing one has to keep in reference libraries in schools or colleges.

Having read this book, one must confess its immense load on the reader, for the book is nowhere near to 'one-sitting' read. Its load of information, coming in various points of view from the authors engages the reader with unforgiving transaction. It would be apt to call it a herculean task for general students, for they are compelled to refer to other sources to clarify and expose themselves to the matters, concepts, works cited, people quoted very often and the regions and cultures that are most discussed in the course.

$$
* * *
$$

\section{Cite this work:}

VINAY S. M. 2020. Untranslatability: Interdisciplinary Perspectives. Review of Untranslatability: Interdisciplinary Perspectives, by Large, Duncan; Motoko Akashi; Wanda Jozwikowska and Emily Rose. (eds.). Translation Today, Vol. 14(1). 124-128. DOI: 10.46623/tt/2020.14.1.br1 